\title{
Cold spray for reducing venopuncture pain in hemodialysis patients; a randomized double-blinded controlled trial
}

\author{
Zahra Shafii ${ }^{*}$, Neshiman Abdi Bastami ${ }^{1}$, Amir Ahmad Nasiri ${ }^{2}$ \\ ${ }^{1}$ Rajaie Cardiovascular Medical and Research Center, Iran University of Medical Sciences, Tehran, Iran \\ ${ }^{2}$ Imam Hossein Hospital, Shahid-Beheshti University of Medical sciences, Tehran, Iran
}

\section{AR T I C L E I N F O}

Article Type:

Original

\section{Article History:}

Received: 10 February 2019

Accepted: 3 June 2019

Published online: 20 July 2019

\section{Keywords:}

Hemodialysis

Cannulation

Vapocoolant

Pain

\begin{abstract}
A B S T R A C T
Introduction: The pain due to cannulation and needle insertion into blood vessels becomes problematic among patients suffering hemodialysis.

Objectives: The present study aimed to assess the pain relieving effects of cooling sprays among patients undergoing hemodialysis.

Patients and Methods: Eighty patients aged higher than 18 years who were on chronic hemodialysis were randomly assigned into two groups including the group received cooling spray for relieving pain $(n=40)$ and the group received stilled water as placebo $(n=40)$. In the intervention group and in a hemodialysis session, 2 puffs of the Cramer Cold Spray were sprayed 30 seconds before the cannulation. The pain severity was assessed by the visual analogue scale (VAS) method.

Results: The mean of pain severity score was not different between the intervention and control group before intervention, however after intervention, the patients in the intervention group experienced milder pain due to cannulation as compared to control group $(3.28 \pm 1.13$ versus 5.30 $\pm 1.76 ; P<0.001$ ). Interviewing with the patients receiving cooling spray showed willingness to the use of spray in $87.5 \%$ of cases. The local complication due to the use of cold spray was revealed only in $5 \%$ of patients.

Conclusion: The use of cooling spray in hemodialysis patients can reduce the pain caused by needle insertion. This method can be routinely used as a non-pharmacological pain relief method to reduce pain in hemodialysis patients

Trial registration: Registration of trial protocol has been approved in Iranian registry of clinical trials website (identifier: IRCT20180108038262N1; https://irct.ir/trial/28874).
\end{abstract}

Implication for health policy/practice/research/medical education:

Cooling sprays can be used as a safe, effective and easy method for reducing the pain caused by needle insertion in hemodialysis patients.

Please cite this paper as: Shafii Z, Abdi Bastami N, Nasiri AA. Cold spray for reducing venopuncture pain in hemodialysis patients; a randomized double-blinded controlled trial. J Nephropharmacol. 2020;9(1):e01. DOI: 10.15171/npj.2020.01

\section{Introduction}

The advancement in medical technology has prolonged the longevity of people suffering from chronic renal insufficiency (1). Despite all these improvements, the patients are still affected by the physiological stressors due to the nature of disease as well as therapeutic maintenance such as hemodialysis. Among physiological stressors, it can be pointed to pain during and after hemodialysis (2). Regarding the necessity of continuously using arterial and venous needles for access to vessels in hemodialysis (3), these patients experience at least 300 needle-related pain each year (4). Pain is an unpleasant sensation and an emotional experience that is associated with potential or actual tissue damage and is one of the unpleasant complications in dialysis patients (5). Pain not only results from the nature of the disease, but may also be derived from many invasive diagnostic and therapeutic procedures (6). Diagnostic treatments are among the most stressful medical events (7). Studies have shown that about 3.5\% of adult patients are very scared and $22 \%$ have a moderate fear of needles. The pain caused by the insertion of needles and catheters into blood vessels becomes problematic when it is repeated and requires constant use of them. In the treatment of patients with chronic renal failure, hemodialysis as a preservative usually requires continuous use of arterial and venous needles for the patient (8). 
Many improvements have been recently made in the treatment of pain, since several pharmaceutical and noninvasive methods have been proposed to relieve pain. However, in some cases, the effect of these methods on the pain reduction of patients is questionable (9). Moreover, due to the side effects of drugs, the use of non-medicated methods for controlling and relieving pain is in progress today. One of these non-pharmacological methods is the use of cooling sprays (10). Due to the immediate relief of pain in athletes following the use of cooling sprays $(11,12)$, it seems that they can be used to reduce the pain caused by needling among hemodialysis patients.

\section{Objectives}

The present study aimed to assess the pain relieving effects and complications of cooling sprays among patients undergoing hemodialysis.

\section{Patients and Methods}

\section{Patients}

This randomized double-blinded controlled trial on patients aged higher than 18 years who suffering hemodialysis admitted to two great referral hospitals in Tehran, Iran (2018). The exclusion criteria were unwillingness to participate in the study, sensitivity to alcoholic beverages, pregnancy, the use of analgesics within 24 hours prior to needling, the presence of mental problems and inability to fill questionnaire and collaboration, non-persistent hemodialysis, cooperation in another study, skin reaction at the pinching site, or anesthetizing organs with vascular access. The eligible patients were randomly (using the random allocation version 1.2 software) assigned into two groups, including the group received cooling spray for relieving pain (as the intervention group, $n=40$ ) and the group did not receive this relieving pain method (as the control group, $\mathrm{n}=40$ ). In the intervention group and in a hemodialysis session, two puffs of the Cramer Cold Spray were sprayed 30 seconds before the cavitation. After 30 seconds, the cannulation was performed and the questionnaire was fulfilled again. The contents of the cooling spray include butane, isobutane, propane, perfume, and limonene. In the control group, distilled water was administered as placebo. The pain severity was assessed by the visual analogue scale (VAS) method scored as 0 for the mildest pain and 10 for the most severe pain. Figure 1 shows the CONSORT of the study.

\section{Ethical issues}

The research followed the tents of the Declaration of Helsinki. The Ethics Committee of Iran University of Medical Sciences approved this study (RHC.AC.IR.

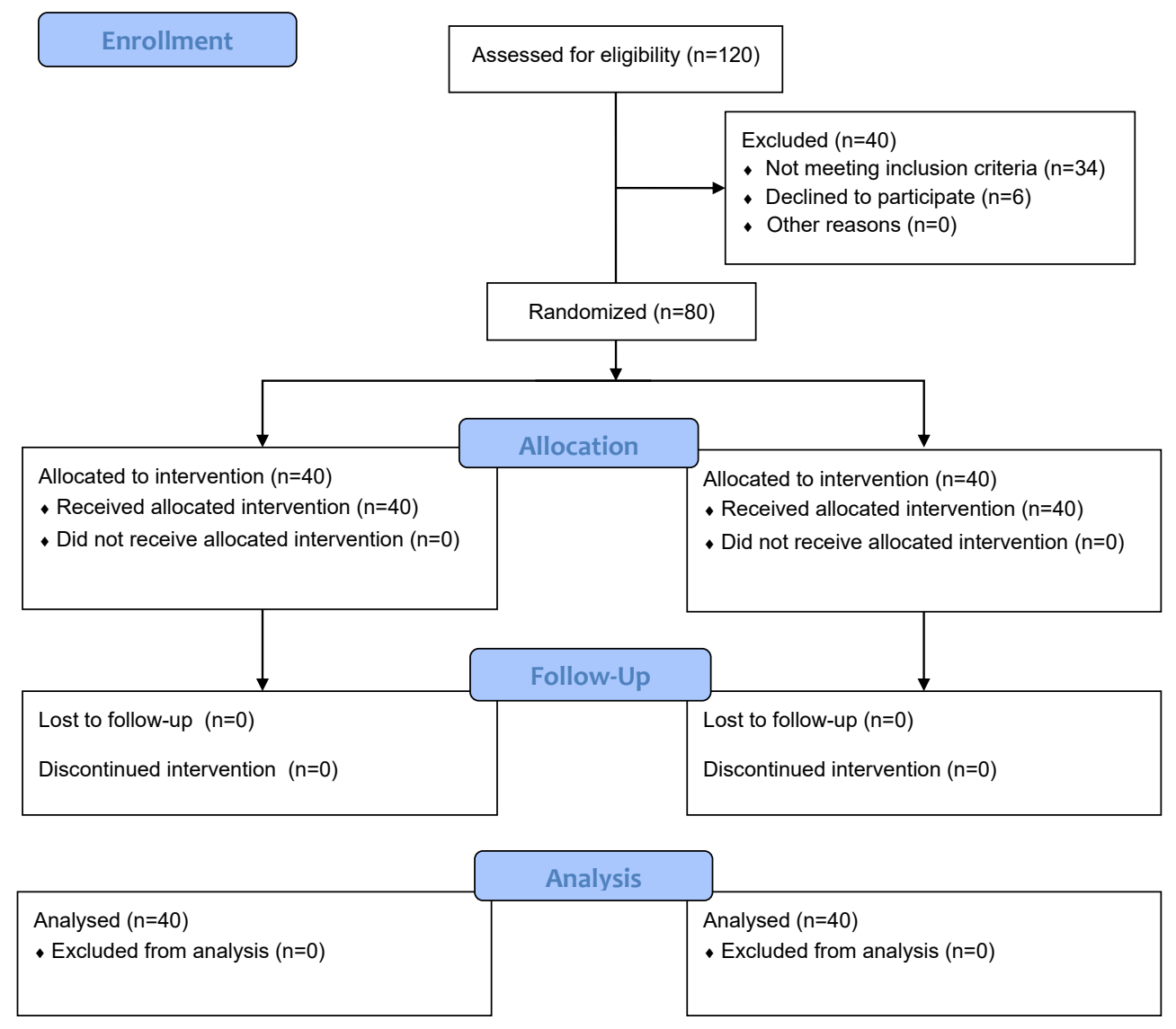

Figure 1. CONSORT diagram of the study. 
REC.1396.43). All study protocols were approved by the institutional ethical committee at Shahid-Rajaei Heart center and at Iran University of Medical Sciences and registered as a clinical trial at Iranian Registry of Clinical Trials (identifier: IRCT20180108038262N1; https://irct. $\mathrm{ir} /$ trial/28874). In addition, written informed consent was taken from all participants before any intervention.This work has been conducted as part of MSc of Critical care nursing thesis of Neshiman Bastami in Iran University of Medical Sciences, Tehran, Iran.

\section{Data analysis}

Patients' demographic information was collected using a checklist and by reviewing the hospital recorded files. Descriptive analysis was used to describe the data, including mean \pm standard deviation (SD) for quantitative variables and frequency (percentage) for categorical variables. Chi-square test, $t$ test, or Mann-Whitney $U$ test were applied for comparison of variables. For the statistical analysis, the statistical software IBM SPSS Statistics for Windows version 22.0 (IBM Corp. Released 2013, Armonk, New York) was used. $P$ values $<0.05$ were considered statistically significant.

\section{Results}

Baseline characteristics in the intervention and control groups are summarized in Table 1. Comparing characteristics across the two groups showed no difference in gender, age, body mass index (BMI), educational level, job status, medical history including smoking, diabetes mellitus and hypertension, reasons for renal failure as well as the duration of dialysis and cannulation. As shown in Table 2, the mean of pain severity score was not different between the intervention and control group before intervention, however the patients in the intervention group experienced milder pain due to cannulation as compared to control group $(3.28 \pm 1.13$ versus $5.30 \pm$ 1.76; $P<0.001)$. Interviewing with the patients receiving cooling spray showed willingness to the use of spray in the following experiences in $87.5 \%$. The local complication due to the use of cold spray was revealed only in $5 \%$ of patients.

\section{Discussion}

The aim of this study was to investigate the effect of cold spray on pain induced by needle entry in hemodialysis patients. In this study, the pain scores of patients in the intervention group were compared with the control group. The results showed that the administration of cooling spray reduces the pain induced by needle entry in hemodialysis patients, which was statistically significant between the two groups. The researcher's hypothesis that the use of cold spray has been effective in reducing pain was successfully confirmed. Different methods have been used to reduce the pain caused by needle entry in such patients. In a study by Fangin et al (13), the use of cryotherapy is effective in reducing pain in the patient, which is consistent with the results of this study. In another study by Hassan et al (14), using cryotherapy could reduce the pain of fistula catheterization in children under hemodialysis. Our current hypothesis came from the fact that cooling sprays have been very effective on athletes with acute injuries during sporting events. Also, some experiments could demonstrate the efficacy of cooling on pain caused by needling in clinical settings. Likewise, in a study by Griffith et al (15), the administration of a vapocoolant immediately before intravenous cannulation reduced pain as well as discomfort during the procedure. Accordingly, in a study by Hijazi et al in 2009 (16), topical alkane vapocoolant spray is effective, acceptable, and safe in reducing pain with peripheral intravenous cannulation in adults in the emergency department. The studies on the impact of vapocoolant sprays for relieving pain with intravenous cannulation have revealed inconsistent results. Some studies showed ethyl-chloride to be effective $(17,18)$, while two others found ethylchloride and fluorohydrocarbon $(19,20)$ respectively, to be

Table 1. Baseline information in the intervention and placebo groups

\begin{tabular}{|c|c|c|c|}
\hline Item & $\begin{array}{l}\text { Intervention } \\
\text { group }\end{array}$ & $\begin{array}{l}\text { Control } \\
\text { group }\end{array}$ & $P$ value \\
\hline Mean age, year & $58.93 \pm 12.26$ & $60.03 \pm 14.29$ & 0.713 \\
\hline Mean BMI, kg/m² & $25.03 \pm 3.85$ & $24.24 \pm 4.32$ & 0.394 \\
\hline Gender & & & 0.816 \\
\hline Male & $25(62.5)$ & $26(65.0)$ & \\
\hline Female & $15(37.5)$ & $14(35.0)$ & \\
\hline Education level & & & 0.201 \\
\hline Undergraduate & $31(77.5)$ & $27(67.5)$ & \\
\hline Diploma & $7(17.5)$ & $8(20.0)$ & \\
\hline Associate degree & $0(0.0)$ & $4(10.0)$ & \\
\hline Master degree & $2(5.0)$ & $1(2.5)$ & \\
\hline Occupational level & & & 0.690 \\
\hline Employed & $11(27.5)$ & $10(25.0)$ & \\
\hline Self-employed & $15(37.5)$ & $16(40.0)$ & \\
\hline Worker & $0(0.0)$ & $2(5.0)$ & \\
\hline Housewife & $14(35.0)$ & $12(30.0)$ & \\
\hline History of smoking & $6(15.0)$ & $10(25.0)$ & 0.402 \\
\hline History of diabetes & $20(50.0)$ & $13(32.5)$ & 0.112 \\
\hline History of hypertension & $27(67.5)$ & $30(75)$ & 0.459 \\
\hline Cause for renal failure & & & 0.438 \\
\hline Diabetes and hypertension & $13(32.5)$ & $11(27.5)$ & \\
\hline Diabetes alone & $7(17.5)$ & $4(10.0)$ & \\
\hline Hypertension alone & $13(32.5)$ & $20(50.0)$ & \\
\hline Duration of dialysis, month & $50.35 \pm 55.45$ & $44.50 \pm 47.32$ & 0.610 \\
\hline $\begin{array}{l}\text { Duration of cannulation, } \\
\text { month }\end{array}$ & $46.10 \pm 54.09$ & $32.47 \pm 32.03$ & 0.174 \\
\hline
\end{tabular}


Table 2. Pain severity before and after intervention (Mann-Whitney $U$ test)

\begin{tabular}{lccc}
\hline Item & $\begin{array}{c}\text { Intervention } \\
\text { group }\end{array}$ & $\begin{array}{c}\text { Control } \\
\text { group }\end{array}$ & P value \\
\hline Pain score (before intervention) & $6.68 \pm 1.49$ & $5.05 \pm 1.78$ & - \\
Pain score (after intervention) & $3.28 \pm 1.13$ & $5.30 \pm 1.76$ & - \\
Pain reduction & $3.4 \pm 1.53$ & $-0.27 \pm 0.68$ & $<0.001$ \\
\hline
\end{tabular}

ineffective. In a systematic review, Hogan et al, concluded; "vapocoolants were ineffective in children and adults when compared to placebo, and effective in adults only when compared to no treatment" (21). These contradictory results could be related to the variations in cannula size, duration and distance of spray, small sample sizes, and lack of blinding. In our trial, we used spray including butane, isobutane, propane, perfume, and limonene that seems to be very effective in our trial especially in our patients that suffering repeated vascular cannulation.

Today, most hemodialysis patients prefer nonpharmacological methods for pain relief. Using the cryotherapy technique reduces the temperature in the painful area and inflammation, which reduces the intensity and duration of nerve conduction (22). The use of cooling to relieve pain has been employed since Hippocrates in the fourth century BC (23). Cooling the tissue also induce vasoconstriction, which may decrease swelling and ecchymosis (24). In this regard, the American Society for Dermatologic Surgery guidelines now recommends pre-injection use of ice or cooling devices (25). However, it should be noted that considering some confounding factors such as duration of using spray, the number of cannulation, different chemical contents of sprays and disease duration as well as psychological background of patients is necessary to achieve perfect and reliable results. Considering the need for frequent venopuncture in hemodialysis patients, evaluation of the effect and adverse events of this method is necessary.

\section{Conclusion}

In general, the findings of this study showed that the administration of cooling spray in hemodialysis patients can reduce the pain caused by needle insertion without causing serious complications. These results can be used as an independent intervention to dialysis nurses to manage pain in the patients. Additionally, this method can normally be used as a non-pharmacological relief method to reduce pain in hemodialysis patients.

\section{Limitations of the study}

Our limitations were the small sample size and short duration of the intervention.

\section{Authors' contribution}

ZSH designed the experiment. ZSH and AAN supervised the project. AAN and NAB participated in collecting data.
All authors discussed the results and commented on the final manuscript.

\section{Conflicts of interest}

There were no points of conflicts to declare.

\section{Ethical considerations}

Ethical issues (including plagiarism, double publication) have been completely observed by the authors. This article does not contain any studies with animals performed by any of the authors.

\section{Funding/Support}

None.

\section{References}

1. Wong SP, Margaret KY, Green PK, Liu CF, Hebert PL, O'Hare AM. End-of-life care for patients with advanced kidney disease in the US veterans' affairs health care system. Am J Kidney Dis. 2018;72:42-49. doi: 10.1053/j. ajkd.2017.11.007.

2. Harris TJ, Nazir R, Khetpal P, Peterson RA, Chava P, Patel SS. Pain, sleep disturbance and survival in hemodialysis patients. Nephrol Dial Transplant. 2012;27:758-65. doi: 10.1093/ndt/gfr355.

3. Kopple JD, Shapiro BB, Feroze U, Kim JC, Zhang M, Li Y. Hemodialysis treatment engenders anxiety and emotional distress. Clin Nephrol. 2017;88:205-217. doi: 10.5414/ CN109112.

4. Figueiredo AE, Viegas A, Monteiro M, Poli-de-Figueiredo CE. Research in to pain perception with arteriovenous fistula (AVF) cannulation. J Ren Care. 2008;34:169-72. doi: 10.1111/j.1755-6686.2008.00041.x.

5. Konstantinidou E, Koukouvou G, Kouidi E, Deligiannis A, Tourkantonis A. Exercise training in patients with endstage renal disease on hemodialysis: comparison of three rehabilitation programs. J Rehabil Med. 2002;34:40-5.

6. Nonoyama ML, Brooks D, Ponikvar A, Jassal SV, Kontos P, Devins GM, et al. Exercise program to enhance physical performance and quality of life of older hemodialysis patients: a feasibility study. Int Urol Nephrol. 2010;42:11251130. doi: $10.1007 / \mathrm{s} 11255-010-9718-7$

7. Page DE, Taylor DM. Vapocoolant spray vs subcutaneous lidocaine injection for reducing the pain of intravenous cannulation: a randomized, controlled, clinical trial. $\mathrm{Br} \mathrm{J}$ Anaesth. 2010; 105:519-25. doi: 10.1093/bja/aeq198.

8. Rose JB, Galinkin JL, Jantzen EC, Chiavacci RM. A study of lidocaineiontophoresis for pediatric venipuncture. Anesth Analg. 2002;94:867-71.

9. Salehi K, Mohamadi I, Torkamaan G Movasaghi S. The influence of trans-coetaneous electrical nerve stimulation on osteoarthritis patients' pain and quality of life. Daneshvar Med. 2007;14:59-66.

10. Ellis $\mathrm{M}$. The treatment of pain by ethyl chloride and other cooling sprays. Practitioner. 1961;187:367-70.

11. Shadgan B, Med S, Pakravan AH, Hoens A, Reid WD. Subcutaneous and intramuscular hemodynamics and oxygenation after cold spray application as monitored by near-infrared spectroscopy. J Athl Train. 2015; 50:800-5. 
doi: $\quad 10.4085 / 1062-6050-50.6 .02$.

12. Bongers CC, Hopman MT, Eijsvogels TM. Cooling interventions for athletes: An overview of effectiveness, physiological mechanisms, and practical considerations. Temperature (Austin). 2017; 4:60-78. doi: 10.1080/23328940.2016.1277003.

13. Fang L, Hung CH, Wu SL, Fang SH, Stocker J. The effects of cryotherapy in relieving postarthroscopy pain. J Clin Nurs. 2012; 21:636-43. doi: 10.1111/j.1365-2702.2010.03531.x.

14. Hassan A, Darwish MM, El-Samman GA, Fadel FI. The impact of cryotherapy on pain intensity at puncture sites of arteriovenous fistula among children undergoing hemodialysis. J Am Sci. 2012;8:1490-50o.

15. Griffith RJ1, Jordan V, Herd D, Reed PW, Dalziel SR. Vapocoolants (cold spray) for pain treatment during intravenous cannulation. Cochrane Database Syst Rev. 2016;4:CD009484. doi: 10.1002/14651858.CD009484.pub2.

16. Hijazi R, Taylor D, Richardson J. Effect of topical alkane vapocoolant spray on pain with intravenous cannulation in patients in emergency departments: randomized double blind placebo controlled trial. BMJ. 2009;338:b215. doi: 10.1136/bmj.b215.

17. Selby IR, Bowles BJ. Analgesia for venous cannulation: a comparison of EMLA (5 minutes application), lignocaine, ethyl chloride, and nothing. J R Soc Med. 1995; 88:264-7.

18. Armstrong P, Young C, McKeown D. Ethyl chloride and venepuncture pain: a comparison with intradermal lidocaine. Can J Anaesth. 1990; 37:656-8.

19. Hartstein BH, Barry JD. Mitigation of pain during intravenous catheter placement using a topical skin coolant in the emergency department. Emerg Med J. 2008;25:25761. doi: 10.1136/emj.2006.044776.

20. Biro P, Meier T, Cummins AS. Comparison of topical anesthesia methods for venous cannulation in adults. Eur J Pain 1997; 1:37-42.

21. Hogan ME, Smart S, Shah V, Taddio A. A systematic review of vapocoolants for reducing pain from venipuncture and venous cannulation in children and adults. J Emerg Med. 2014;47:736-49. doi: 10.1016/j.jemermed.2014.06.028.

22. Hughes J, ed. Pain Management: From Basics to Clinical Practice. Elsevier Health Sciences; 2008

23. Physical methods for treatment of pain. In: Auerbach: Wilderness Medicine. 5th ed. Mosby; 2007.

24. Matarasso SL, Carruthers JD, Jewell ML. Consensus recommendations for soft-tissue augmentation with nonanimal stabilized hyaluronic acid (Restylane) Plast Reconstr Surg. 2006;117:3S-34S.

25. Alam M, Gladstone H, Kramer EM. ASDS guidelines of care: injectable fillers. Dermatol Surg. 2008; 34 Suppl 1:S115-48. doi: 10.1111/j.1524-4725.2008.34253.x.

Copyright $\odot 2020$ The Author(s); Published by Published by Society of Diabetic Nephropathy Prevention. This is an open-access article distributed under the terms of the Creative Commons Attribution License (http://creativecommons.org/licenses/by/4.0), which permits unrestricted use, distribution, and reproduction in any medium, provided the original work is properly cited. 